Results: There were no significant differences in gender, age, clinical manifestations, and laboratory findings between IgAV and IgAVN patients (Table 1). sCD40L levels were higher (median $1938.1 \mathrm{vs} 754.9 \mathrm{pg} / \mathrm{mL}, \mathrm{p}=0.04$ ) whereas sST2 levels were lower (median 862.8 vs $2302.8 \mathrm{pg} / \mathrm{mL}, \mathrm{p}=0.02$ ) in the patients who developed IgAV nephritis (Figure 1). sRAGE levels were higher and IL18 levels were lower in IgAVN patients but did not reach statistical significance, probably due to the low number of patients. The other parameters did not show any specific pattern.

Table 1.

\begin{tabular}{lccc}
\hline & $\operatorname{lgAV}(\mathrm{n}=4)$ & $\operatorname{lgAVN}(\mathrm{n}=4)$ & $\mathrm{p}$ value \\
\hline Gender & $2 \mathrm{~F}, 2 \mathrm{M}$ & $1 \mathrm{~F}, 3 \mathrm{M}$ & 0.49 \\
Age at disease onset & $9.0 \pm 5.4$ & $10.3 \pm 3.4$ & 0.68 \\
Arthralgia/arthritis & $50 \%$ & $75 \%$ & 0.49 \\
GIS involvement & $75 \%$ & $50 \%$ & 0.49 \\
Haemoglobine $(\mathrm{gr} / \mathrm{dL})$ & $12.4 \pm 2.3$ & $12.3 \pm 0.6$ & 0.95 \\
White blood cells, $\times 10^{9} / \mathrm{L}$ & $11150 \pm 1933$ & $8525 \pm 1497$ & 0.08 \\
Platelets $\times 10^{9} / \mathrm{L}$ & $290250 \pm 87328$ & $269250 \pm 38741$ & 0.68 \\
Erythrocyte sedimentation rate $(\mathrm{mm} / \mathrm{hr})$ & $10.5 \pm 9.1$ & $21.0 \pm 14$ & 0.26 \\
C-reactive protein $(\mathrm{mg} / \mathrm{dL})$ & $0.63 \pm 0.03$ & $1.16 \pm 0.96$ & 0.39 \\
Data are given as mean $\pm \mathrm{SD}$ & & &
\end{tabular}

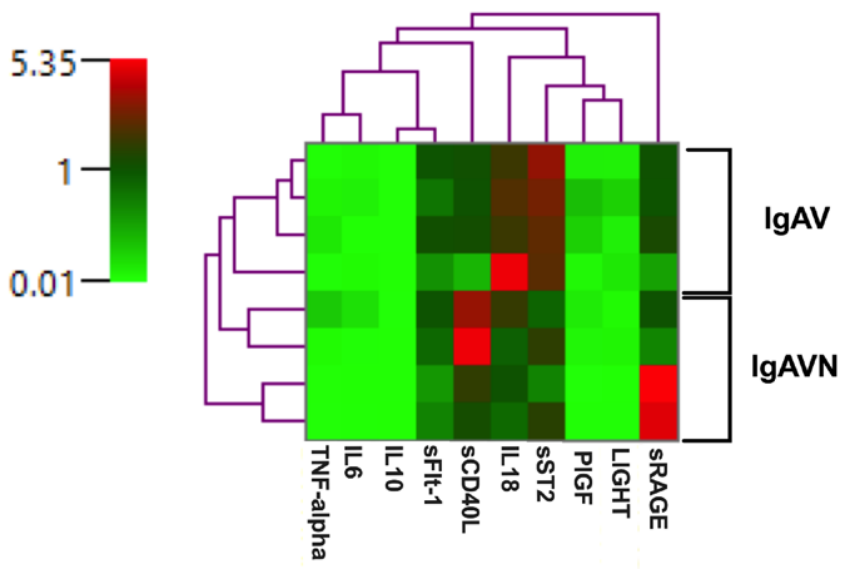

Figure 1.

Soluble CD40 ligand (SCD40L) is expressed on platelets and released on activation. It is proinflammatory for endothelial cells and promotes coagulation by inducing expression of tissue factor on monocytes and endothelial cells ${ }^{2}$. It was investigated in acute coronary syndrome and was suggested as a risk factor for vascular damage. ${ }^{2}$. Furthermore, the levels of SCD40L were shown to be correlated with disease activity in ANCA-associated vasculitis ${ }^{3}$. Thus in IgAV, sCD40L may be associated with the involvement of the kidney vasculature, which represents the more severe form of the disease. Receptor for advanced glycation end-products (RAGE) is another marker for endothelial damage and vasculitis which was higher in IgAVN, as well.

IL33 is expressed by epithelial and endothelial cells and overexpression of IL33 have been shown in large vessel vasculitis ${ }^{4}$. sST2 acts as a decoy receptor and inhibits IL33 signalling ${ }^{4}$. It was interesting to see that the levels of the IL-18 and sST2, which are members of IL-1 family, were lower in IgAVN patients.

Conclusion: Although the number of the patients were limited in this pilot study, we suggest that SCD40L and SRAGE might be used to predict the development of renal disease in IgAV patients. Further studies with larger number of patients are needed to confirm our findings.

REFERENCES:

[1] Sag E, Batu ED, Ozen S. Childhood systemic vasculitis. Best practice \& research Clinical rheumatology 2017;31(4):558-75.

[2] Heeschen C, Dimmeler S, Hamm CW, et al. Soluble CD40 ligand in acute coronary syndromes. The New England journal of medicine 2003;348(12):1104-11.

[3] Tomasson G, Lavalley M, Tanriverdi K, et al. Relationship between markers of platelet activation and inflammation with disease activity in Wegener's granulomatosis. The Journal of rheumatology 2011;38(6):1048-54.

[4] Desbois AC, Cacoub P, Leroyer AS, et al. Immunomodulatory role of Interleukin-33 in large vessel vasculitis. Sci Rep 2020;10(1):6405.

Disclosure of Interests: None declared.

DOI: 10.1136/annrheumdis-2021-eular.1306

\section{Pediatric Rheumatology - Clinical}

\section{\begin{tabular}{|l|l}
\hline POS0075 SAFETY AND EFFICACY OF GOLIMUMAB FOR \\
\hline
\end{tabular} THE TREATMENT OF POLYARTICULAR JUVENILE IDIOPATHIC ARTHRITIS - AN UPDATE FROM THE BIKER REGISTRY}

A. Zimmer ${ }^{1}$, A. Klein ${ }^{2}$, K. Minden ${ }^{3}$, T. Hospach ${ }^{4}$, F. Weller-Heinemann ${ }^{5}$,

J. Kuemmerle-Deschner ${ }^{6}$, M. Fasshauer ${ }^{7}$, N. Hofmann ${ }^{8}$, H. Koessel ${ }^{9}$,

I. Foeldvari ${ }^{10}$, S. Mrusek ${ }^{11}$, D. Windschall ${ }^{12}$, N. Onken ${ }^{13}, M^{2}$. Hufnagel ${ }^{14}$,

D. Foell ${ }^{15}$, N. Brueck ${ }^{16}$, P. T. Oommen ${ }^{17}$, F. Dressler ${ }^{18}$, A. Helling-Bakki ${ }^{19}$

G. Horneff' ${ }^{2}{ }^{1}$ Kinderklinik St. Augustin, Paediatric Rheumatology, Sankt Augustin, Germany; ${ }^{2}$ Kinderklinik St. Augustin, Paediatric Rheumatology, St. Augustin, Germany; ${ }^{3}$ Charité Universitätsklinik Berlin, Paediatric Rheumatology, Berlin, Germany; ${ }^{4}$ Klinikum Stuttgart- Olgahospital, Paediatric Rheumatology, Stuttgart, Germany; ${ }^{5}$ Klinikum Bremen-Mitte, Professor-Hess-Kinderklinik, Paediatric Rheumatology, Bremen, Germany; ${ }^{6}$ Universitätsklinikum Tübingen, Paediatric Rheumatology, Tübingen, Germany: ${ }^{7}$ Klinikum St. Georg g GmbH, Paediatric Rheumatology, Leipzig, Germany; ${ }^{8}$ Klinikum Bamberg, Sozialstiftung Bamberg, Paediatric Rheumatology, Bamberg, Germany; ${ }^{9}$ Städtisches Klinikum Brandenburg GmbH, Paediatric Rheumatology, Brandenburg, Germany; ${ }^{10}$ Hamburger Zentrum für Kinder- und Jugendrheumatologie am Klinikum Eilbek, Paediatric Rheumatology, Hamburg, Germany; ${ }^{11}$ Praxis für Kinder- und Jugendrheumatologie, Paediatric Rheumatology, BadenBaden, Germany; ${ }^{12}$ Klinik für Kinder- und Jugendrheumatologie, Paediatric Rheumatology, Sendenhorst, Germany; ${ }^{13}$ Kinder- und Jugendärztliche Gemeinschaftspraxis, Paediatric Rheumatology, Lüneburg, Germany; ${ }^{14}$ Universitätsklinikum Freiburg, Paediatric Rheumatology, Freiburg, Germany;

${ }^{15}$ Universitätsklinikum Münster, Paediatric Rheumatology, Münster, Germany;

${ }^{16}$ Universitätsklinikum Carl Gustav Carus, Paediatric Rheumatology, Dresden, Germany; ${ }^{17}$ Universitätskinderklinikum Düsseldorf, Paediatric Rheumatology, Düsseldorf, Germany; ${ }^{18}$ Medizinische Hochschule Hannover, Paediatric Rheumatology, Hannover, Germany; ${ }^{19}$ UniversitätsKlinikum Heidelberg, Paediatric Rheumatology, Heidelberg, Germany

Background: Golimumab (GOL) is approved for treatment of polyarticular juvenile idiopathic arthritis ( $\mathrm{pJIA}$ ) in patients 2 years and older. Data on long-term safety of GOL in this indication are limited.

Objectives: To assess long-term safety and efficacy of GOL in pJIA patients. Methods: In this ongoing non-interventional observational study, clinical characteristics, disease activity and safety parameters were analysed using the German Biologics in Paediatric Rheumatology (BiKeR) registry. 81 pJIA-patients treated with GOL were body weight-matched with 162 patients receiving alt. tumor necrosis factor inhibitors (TNFi) and 81 biologic-naïve patients under methotrexate (MTX)-therapy.

Results: Baseline parameters of GOL patients differed from the alternative TNFi and MTX cohorts. In patients starting with GOL treatment, disease duration was longer, corticosteroid use was less and disease activity, measured by the mean number of active joints and the JADAS10, was lower (Table 1).

The long-term clinical efficacy of GOL in pJIA is highlighted by a decrease of the mean JADAS 10 from 11.6 (baseline) to 5.2 after 24 months. After 2 years, a JADAS 10 minimal disease activity was reached by $44.4 \%$ of patients, whereas $22.2 \%$ of patients were in remission and the JIA ACR 30/50/70/90 response rates were $77.8 / 72.2 / 66.7 / 55.6 \%$ respectively.

$\mathrm{AE}, \mathrm{SAE}$ and infectious $\mathrm{AE}$ rates between the three cohorts were comparable (Table 1). In the GOL cohort, 4 SAE (1 uveitis, 1 arthritis flare, 1 fibromyalgia syndrome and 1 abscess) were reported, while in the alt. TNFi group 7 SAEs and in the MTX cohort 1 SAE were noted (Table 1). One serious infectious event (1 abscess) was documented in the GOL cohort, 2 alt. TNFi patients had influenza and no serious infectious events were seen in the MTX control group.

Few autoimmune processes occurred: 2 incident events in the GOL cohort (1 uveitis, 1 psoriasis), 3 cases in the alt. TNFi group (2 uveitis, 1 psoriasis,) and 1 event in MTX-patients (celiac disease) (Table 1). Out of the $20 \mathrm{GOL}$ patients with preexisting uveitis at baseline, 6 had flare events; there were no reported uveitis flares of the 17 patients in the alt. TNFi group and no patients with preexisting uveitis in the MTX-group. No malignancies or deaths were reported.

Conclusion: Our interim results show an acceptable safety profile of GOL therapy, comparable to treatment with alt. TNFi or MTX. No new safety signals occurred. The efficacy outcome data confirm long-term benefits of GOL treatment in pJIA patients.

Acknowledgements: We greatly appreciate the kind support of Z. Huang, S. Calhoun.

Disclosure of Interests: Angela Zimmer: None declared, Ariane Klein: None declared, Kirsten Minden: None declared, Toni Hospach: None declared, Frank Weller-Heinemann: None declared, Jasmin Kuemmerle-Deschner: None declared, Maria Fasshauer: None declared, Nadja Hofmann: None declared, Hans Koessel: None declared, Ivan Foeldvari: None declared, Sonja Mrusek: 
Table 1. Baseline parameters and adverse events

\begin{tabular}{|c|c|c|c|c|c|}
\hline & $\begin{array}{l}\text { GOL } \\
n=81\end{array}$ & $\begin{array}{c}\text { alt. TNFi } \\
n=162\end{array}$ & $\begin{array}{l}\text { MTX } \\
n=81\end{array}$ & $\begin{array}{l}\text { p-value } \infty \\
\text { GOL vs alt. } \\
\text { TNFi }\end{array}$ & $\begin{array}{c}\text { p-value } \infty \\
\text { GOL vs } \\
\text { MTX }\end{array}$ \\
\hline Gender female ${ }^{\circ}$ & $67(83)$ & $127(78)$ & $64(79)$ & 0.5 & 0.7 \\
\hline Disease duration (yrs) & $7.1 \pm 4.3$ & $4.3 \pm 3.7$ & $1.2 \pm 2.1$ & $<0.0001$ & $<0.0001$ \\
\hline RF neg. Polyarthritis ${ }^{\circ}$ & $40(49)$ & $79(49)$ & $50(62)$ & 1.0 & 0.15 \\
\hline RF pos. Polyarthritis ${ }^{\circ}$ & $8(10)$ & $22(14)$ & $16(20)$ & 0.5 & 0.1 \\
\hline Extended Oligoarthritis ${ }^{\circ}$ & $30(37)$ & $54(33)$ & $13(16)$ & 0.6 & 0.004 \\
\hline Psoriatic arthritis ${ }^{\circ}$ & $3(4)$ & $7(4)$ & $2(3)$ & $1.0 / 1.0$ & 1.0 \\
\hline Pretreatment bDMARD ${ }^{\circ}$ & $68(84.0)$ & $35(21.6)$ & 0 & $<0.0001$ & $<0.0001$ \\
\hline $\begin{array}{l}\text { Concomitant systemic } \\
\text { steroids, } \mathrm{n}(\%)\end{array}$ & $13(16)$ & $38(24)$ & $39(48)$ & 0.2 & $<0.0001$ \\
\hline Active joint count \# & $4.6 \pm 4.8$ & $4.9 \pm 5.7$ & $9.6 \pm 6.5$ & 0.4 & $<0.0001$ \\
\hline CHAQ DI \# & $0.4 \pm 0.5$ & $0.5 \pm 0.5$ & $0.6 \pm 0.6$ & 0.1 & 0.02 \\
\hline JADAS10 \# & $11.6 \pm 6.2$ & $12.1 \pm 6.1$ & $16.8 \pm 5.3$ & 0.6 & $<0.0001$ \\
\hline$A E$ * & $\begin{array}{l}91(107.4 ; \\
88-132)\end{array}$ & $\begin{array}{l}213(88.7 \\
78-101)\end{array}$ & $\begin{array}{c}113(119.8 \\
100-144)\end{array}$ & 0.1 & 0.4 \\
\hline SAE * & $4(4.7 ; 2-13)$ & $7(2.9 ; 1-6)$ & $1(1.1 ; 0.1-8)$ & 0.4 & 0.2 \\
\hline Serious infections * & $1(1.2 ; 0.2-8.4)$ & $2(0.8 ; 0.2-3.3)$ & 0 & 0.7 & n.a. \\
\hline Autoimmune process (\%) & $2(2.4)$ & $3(1.9)$ & $1(1.2)$ & 1.0 & 1.0 \\
\hline $\begin{array}{l}\text { Patients with uveitis new } \\
\text { manifestation after } \\
\text { study entry * }\end{array}$ & $1(1.2 ; 0.2-8)$ & $2(0.8 ; 0.5-3)$ & 0 & 0.7 & n.a. \\
\hline $\begin{array}{l}\text { Patients with uveitis flare } \\
\text { events with preexisting } \\
\text { uveitis at baseline* }\end{array}$ & $6(7.1 ; 3-16)$ & 0 & 0 & n.a. & n.a. \\
\hline
\end{tabular}

childhood health assessment questionnaire disability index ( $\mathrm{CHAQ} \mathrm{Di}$ ), juvenile arthritis disease activity index (JADAS), adverse event (AE), patient year (PY), ${ }^{\circ} \mathrm{n}(\%)$, \# mean (SD), * $\mathrm{n}$ (rate/100PY; 95\% Cl), Golimumab (GOL), alternative tumor necrosis factor inhibitor (alt. TNFi), methotrexate (MTX), $\infty$ by t-test or $\chi 2$-test as appropriate.

None declared, Daniel Windschall: None declared, Nils Onken: None declared, Markus Hufnagel: None declared, Dirk Foell: None declared, Normi Brueck: None declared, Prassad Thomas Oommen: None declared, Frank Dressler: None declared, Astrid Helling-Bakki: None declared, Gerd Horneff Speakers bureau: MSD.

DOI: 10.1136/annrheumdis-2021-eular.2145

\section{POS0076 \\ S100A8/A9 AND S100A12 AS POTENTIAL PREDICTIVE BIOMARKERS OF ABATACEPT RESPONSE IN POLYARTICULAR JUVENILE IDIOPATHIC ARTHRITIS}

N. Ruperto $^{1}$, G. Schulert ${ }^{2}$, A. Sproles ${ }^{2,3}$, S. Thornton ${ }^{2,3}$, G. Vega Cornejo ${ }^{4}$, J. Anton ${ }^{5}$, R. Cuttica ${ }^{6}$, M. Henrickson ${ }^{2}$, I. Foeldvari ${ }^{7}$, D. Kingsbury ${ }^{8}$, M. Askelson ${ }^{9}$, J. Liu ${ }^{10}$, S. Mukherjee ${ }^{11}$, R. Wong ${ }^{12}$, D. J. Lovell ${ }^{13}$, A. Martini $^{14}$, A. Grom ${ }^{2}, \mathrm{H}$. Brunner ${ }^{2}$ on behalf of Pediatric Rheumatology Collaborative Study Group (PRCSG) and Paediatric Rheumatology International Trials Organisation (PRINTO). ${ }^{1}$ IRCCS Istituto Giannina Gaslini, Clinica Pediatrica e Reumatologia, Genova, Italy; ${ }^{2}$ Cincinnati Children's Hospital Medical Center, Division of Rheumatology, Cincinnati, United States of America; ${ }^{3}$ University of Cincinnati College of Medicine, Department of Pediatrics, Cincinnati, United States of America; ${ }^{4}$ Hospital México Americano, CREA, Guadalajara, Mexico; ${ }^{5} \mathrm{Hospital}$ Sant Joan de Déu, Division of Pediatric Rheumatology, Barcelona, Spain; ${ }^{6}$ Hospital General de Niños Pedro de Elizalde, Pediatric Rheumatology, Buenos Aires, Argentina; ${ }^{7}$ Hamburg Centre for Pediatric and Adolescent Rheumatology, Schön Klinik Hamburg Eilbek, N/A, Hamburg, Germany; ${ }^{8}$ Randall Children's Hospital at Legacy Emanuel, Division of Rheumatology, Portland, United States of America; ${ }^{9}$ Bristol Myers Squibb, Global Biometric Sciences, Princeton, United States of America; ${ }^{10}$ Bristol Myers Squibb, Translational Medicine, Princeton, United States of America; ${ }^{11}$ Bristol Myers Squibb (at the time of analysis), Translational Medicine, Princeton, United States of America; ${ }^{12}$ Bristol Myers Squibb, Immunology and Fibrosis, Princeton, United States of America; ${ }^{13}$ Cincinnati Children's Hospital Medical Center, Department of Pediatrics, Division of Rheumatology, Cincinnati, United States of America; ${ }^{14}$ University of Genoa, N/A, Genoa, Italy

Background: The calcium-binding proteins S100A8/A9 (calprotectin) and S100A12 (extracellular newly identified receptor for advanced glycation end-products binding protein [EN-RAGE]) are involved in multiple signalling pathways to mediate inflammation, can be secreted by activated monocytes/macrophages and exhibit cytokine-like extracellular functions. Circulating levels of these proteins have been associated with disease and clinical responses in systemic juvenile idiopathic arthritis (sJIA), including treatment response. ${ }^{1}$ Studies suggest that serum S100A8/A9 and S100A12, which are released at inflammation sites, are more specific biomarkers of local inflammation (e.g. in the synovium) than systemic biomarkers such as CRP and ESR., ${ }^{2,3}$

Objectives: To investigate if baseline S100A8/A9 and S100A12 predict clinical response to abatacept treatment in polyarticular JIA (pJIA), and to assess whether changes from baseline in S100A8/A9 or S100A12 can be better prognostic markers for response to abatacept treatment than CRP in pJIA

Methods: Data are from a phase III trial of SC abatacept for the treatment of pJIA (NCT01844518). ${ }^{4}$ This 24-month, single-arm, open-label, international, multicentre, two-part study included male and female patients with pJIA aged 2-17 years. This analysis examined the correlation between biomarkers (S100A8/A9, S100A12 and high-sensitivity CRP [hsCRP]) and disease activity (measured using Juvenile Arthritis Disease Activity Score [JADAS]) at baseline, baseline biomarker values as predictors of future treatment response (ACR and JADAS endpoints), and the correlation between change from baseline in biomarker values and treatment response at Day 113.

Results: Of 219 total patients, 158 (72\%) had S100A8/A9 values and 155 (71\%) had S100A12 values at baseline. Median S100A8/A9 and S100A12 values were $3295 \mathrm{ng} / \mathrm{mL}$ (normal range, $716-3004 \mathrm{ng} / \mathrm{mL}$ ) and $176 \mathrm{ng} / \mathrm{mL}$ (normal range, 32 $385 \mathrm{ng} / \mathrm{mL}$ ), respectively. S100A8/A9, S100A12 and hsCRP (median $0.20 \mathrm{mg} /$ $\mathrm{dL}$; normal $\leq 0.6 \mathrm{mg} / \mathrm{dL}$ ) had a low-to-moderate but significant association with disease activity at baseline; coefficients for associations between JADAS71-CRP low disease activity (LDA) and the biomarkers S100A8/A9, S100A12 and hsCRP were $0.23(p=0.0038), 0.16(p=0.0448)$ and $0.26(p=0.0001)$, respectively. Baseline S100A8/A9 level above the median was associated with lower odds of ACR100 at Day $113(p=0.0052)$. Figure 1 shows the associations of baseline biomarker values with Day 113 ACR and JADAS scores in the overall population. Baseline S100A8/A9 or S100A12 did not significantly influence ACR50 or ACR70 responses at Day 113, but high baseline values were associated with reduced odds of ACR90 ( $p=0.01), A C R 100(p=0.005)$, ACR-inactive disease (ID) $(p=0.0001)$, and JADAS71-CRP (LDA) $(p=0.02)$. By Day 477, elevated baseline S100A12 was still significantly associated with lower odds of ACR100 overall $(0.467 ; p=0.0248)$ but baseline $\mathrm{S} 100 \mathrm{~A} 8 / \mathrm{A} 9$ was not; at Day 645 , neither was significantly associated with ACR100 response. At Day 113, changes from baseline in S100A8/A9 and S100A12 were correlated with ACR100 (coefficients of 0.22 $[p=0.0082]$ and $0.26[p=0.0015]$, respectively) and with ACR-ID $(0.22[p=0.0067]$ and 0.26 [ $p=0.0014]$, respectively); change in hsCRP was not significantly correlated with disease response.

Conclusion: S100A8/A9 and S100A12 may serve as prognostic biomarkers to predict response to abatacept treatment at Day 113. Changes from baseline S100A8/A9 and S100A12 levels were more highly correlated with efficacy outcomes including ACR100 and ACR-ID at Day 113 compared with hsCRP.

REFERENCES:

[1] Aljaberi N, et al. Pediatr Rheumatol Online J 2020;18:7.

[2] Hammer H, et al. Arthritis Res Ther 2011;13:R178.

[3] Nordal HH, et al. BMC Musculoskelet Disord 2014;15:335.

[4] Brunner H, et al. Arthritis Rheumatol 2018;70:1144-1154.

Figure 1. Effect of baseline S100AB/A9 or S100A12 level on efficacy response at Day 113 in the overall population

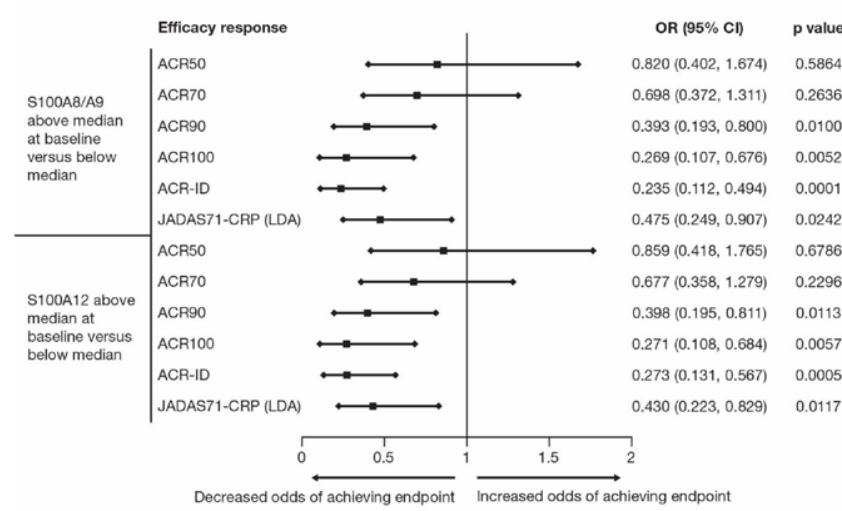

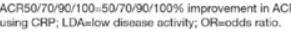

Acknowledgements: Professional medical writing and editorial assistance was provided by Rob Coover, MPH, at Caudex and was funded by Bristol Myers Squibb.

Disclosure of Interests: Nicolino Ruperto Speakers bureau: NR has received honoraria for consultancies or speaker bureaus ( $<10.000$ USD each) from the following pharmaceutical companies in the past 3 years: Ablynx, Astrazeneca-Medimmune, Bayer, Biogen, Boehringer, Bristol Myers Squibb, Celgene, Eli Lilly, EMD Serono, GlaxoSmithKline, Hoffmann-La Roche, Janssen Merck, Novartis, Pfizer, R-Pharma, Sinergie, Sobi and UCB, Consultant of NR has received honoraria for consultancies or speaker bureaus $(<10.000$ USD each) from the following pharmaceutical companies in the past 3 years: Ablynx, Astrazeneca-Medimmune, Bayer, Biogen, Boehringer, Bristol Myers Squibb, Celgene, Eli Lilly, EMD Serono, GlaxoSmithKline, Hoffmann-La Roche, Janssen, Merck, Novartis, Pfizer, R-Pharma, Sinergie, Sobi and UCB, Grant/ 